\title{
Corrosion Behavior of X80 Pipe Steel under HVDC Interference in Sandy Soil
}

\author{
Runzhi Qin ${ }^{1} \oplus$, Yanxia Du ${ }^{1, *}$, Zitao Jiang ${ }^{2}$, Xiuyun Wang ${ }^{2}$, Anqing Fu ${ }^{3}$ and $\mathrm{Yi} \mathrm{Lu}^{4}$ \\ 1 Institute for Advanced Materials and Technology, University of Science and Technology, Beijing 100083, \\ China; lcdcrtgp@hotmail.com \\ 2 Cathodic Protection Computing \& Research Center, Safetech Research Institute (Beijing) Co., Beijing 100083, \\ China; jiangzitao1986@ankosri.com (Z.J.); wxy@ankosri.com (X.W.) \\ 3 Corrosion \& Protection Research Institute, Tubular Goods Research Institute of CNPC, Xi'an 710077, China; \\ fuanqing@cnpc.com.cn \\ 4 Fontana Corrosion Center, Ohio State University, Columbus, OH 43210, USA; luyi0731@gmail.com \\ * Correspondence: duyanxia@ustb.edu.cn; Tel.: +86-010-62333972
}

Received: 9 September 2018; Accepted: 8 October 2018; Published: 10 October 2018

\begin{abstract}
With the development of high voltage direct current (HVDC) systems, some pipelines have been badly interfered. The corrosion mechanism of pipelines has not been clearly clarified. In this work, laboratory experiments were designed to study the corrosion behavior of X80 steel under HVDC interference in sandy soil. The corrosion rates were related to the change in direct current (DC) density, which experienced three stages in the interference process. As soon as high DC interference voltage was applied to the working electrode, the current density increased sharply to a peak value in a few seconds. It then decreased rapidly to a steady value over dozens of seconds. Finally, it remained steady for the remaining time. With the measurement of local soil properties, the change in DC density was attributed to the local soil temperature increment, the water content decrement, and the substantial growth in the soil spread resistance. Moreover, the parameters contribute to the corrosion reaction during the interference process. The corrosion products were characterized at different times of interference via Raman spectroscopy. Lepidocrocite was produced under high DC density and then transformed to hematite under low DC density. Based on the above, the corrosion model during HVDC interference is proposed.
\end{abstract}

Keywords: X80 steel; HVDC interference; direct current density; corrosion behavior

\section{Introduction}

High voltage direct current (HVDC) technology has been widely used for bulk power transmission at long distances. In 1954, the world's first commercial HVDC system was built in Gotland, Sweden. More HVDC systems were then constructed in Europe, North America, and many other regions and countries. HVDC systems develop fast in China because of the advantage of great power, low electrical loss, easy tower configuration, and low construction cost. There are more than 30 systems in construction and operation [1-6].

There are mainly two configurations of HVC systems: bipolar and monopolar. The bipolar configuration is a normal state and the monopolar configuration is usually used in failure or maintenance. When working in a monopolar configuration, a pair of ground electrodes together with the soil is employed as a conductor. In the meantime, a large amount of direct current (DC) is injected into soil, usually in the magnitude of thousands of amps. The current can be absorbed, transmitted, and released by metallic pipe systems nearby, risking personnel safety, equipment damage, and corrosion on the pipeline steel. 
There have been reports on HVDC interference suffered by buried pipelines around the world. In Canada, a section of the pipeline of the Trans Mountain company was interfered by the $260 \mathrm{kV}$ HVDC system nearby. The pipe-to-soil potential (PSP) had a deviation of $400 \mathrm{mV}$ [7]. Moreover, a pipeline system linking Portland Maine with Montreal, Quebec, was interfered by the Quebec-New England Intertie HVDC system. The PSP deviation was $900 \mathrm{mV}$ [8]. In Brazil, an irrigation pipeline was interfered by the Itaipu HVDC system $2.9 \mathrm{~km}$ away. The PSP deviation was as high as $46 \mathrm{~V}$ [9].

The great positive deviation of PSP acts as a potential source of corrosion. Paul [10] designed an experiment and revealed that the well casing model was severely damaged by the HVDC interference. Hopper [11] carried out a series of experiments on HVDC interference. His results showed the leakage current density of the holiday was 3-4 orders of magnitude larger than the average, and the small holidays usually suffered greater interference. When the PSP was $15 \mathrm{~V}_{\mathrm{SCE}}$, the leakage current density could be $2.20 \mathrm{~A} \cdot \mathrm{ft}^{-2}$ in $1.44 \mathrm{ft}^{2}$ holiday, and $8.75 \mathrm{~A} \cdot \mathrm{ft}^{-2}$ in $0.144 \mathrm{ft}^{2}$ holiday, with the corrosion rates of 27.45 and $109.2 \mathrm{~mm} \cdot$ year $^{-1}$, respectively.

Recently, with the construction and operation of HVDC systems in China, some pipelines suffered severe interference when nearby ground electrodes worked in a monopolar configuration. For example, in Xinjiang province, part of the West-East natural gas transmission pipeline was interfered by the Hami electrode. The interfered PSP was $+0.5 \mathrm{~V}_{\mathrm{CSE}}$ and $+4 \mathrm{~V}_{\mathrm{CSE}}[12,13]$. In Guangdong province, a part of the pipeline was interfered by the Tian-Guang HVDC system. When the ground electrode worked in a monopolar configuration, the PSP could reach 150 and $304 \mathrm{~V}_{\mathrm{CSE}}$, which was incredibly high and can bring serious risk to the operation of the pipeline [14,15].

Generally, the HVDC interference cases in China have shown some detail, including the high PSP and large interference distance. The results might be severer than the common DC interference caused by CP systems or metro systems. Though the X80 steel is widely used in the oil and gas industries, its corrosion behavior under HVDC interference are not clear at all. Therefore, research in related fields is necessary to provide theoretical support for the corrosion risk evaluation under HVDC interference.

In this work, based on the interference parameters acquired from the field test, the laboratory experiments were designed to study the corrosion behavior of X80 steel under HVDC interference in sandy soil by a weight loss test, DC parameters, soil properties, and corrosion product characterization.

\section{Materials and Methods}

\subsection{Materials}

The test material was API X80 steel, which was taken from one in-service pipeline system (Xinjiang, China). The metallurgical structure was a combination of ferrite and pearlite. The composition was presented in Table 1. The dimensions of the coupons were $\Phi 18.0 \mathrm{~mm} \times 3.0 \mathrm{~mm}$. In the experiment, the coupons were sealed by a kind of special Poly tetra fluoroethylene fixture [16]. To simulate the holidays on the pipeline, the exposed working area was a circular of $1 \mathrm{~cm}^{2}$.

Table 1. Chemical composition in wt $\%$ of $X 80$ steel.

\begin{tabular}{ccccccccccc}
\hline $\mathbf{C}$ & $\mathbf{M n}$ & $\mathbf{S i}$ & $\mathbf{N i}$ & $\mathbf{C u}$ & $\mathbf{N b}$ & $\mathbf{T i}$ & $\mathbf{S}$ & $\mathbf{P}$ & $\mathbf{M o}$ & $\mathbf{F e}$ \\
\hline 0.070 & 1.61 & 0.21 & 0.12 & 0.14 & 0.041 & 0.012 & 0.0025 & 0.0081 & 0.13 & Balance \\
\hline
\end{tabular}

Before the experiment, the coupons were polished using silicon carbide emery papers of 360, 600, 800, and 1000 grit. The coupons were cleaned by acetone, ethyl alcohol, and de-ionized water and then dried.

\subsection{Soil Sample}

The soil sample was collected $1 \mathrm{~m}$ deep underground in Xinjiang province in Northwest China. It was typical Gobi-Desert sandy soil with a red color, as shown in Figure 1. The water content was $7 \%$, and the soil resistivity was $40 \Omega \cdot \mathrm{m}$, measured by a soil box (M.C. Miller Co., Sebastian, FL, USA). The $\mathrm{pH}$ of the soil was 7.5. The ionic composition was measured and summarized in Table 2. 


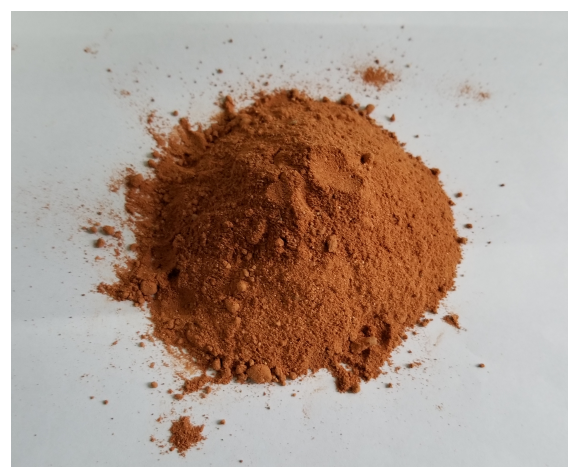

Figure 1. Morphology of the sandy soil.

Table 2. Ionic composition of the red soil in aqueous extract, $\mathrm{mg} \cdot \mathrm{kg}^{-1}$.

\begin{tabular}{ccccccc}
\hline $\mathrm{SO}_{4}{ }^{2-}$ & $\mathrm{NO}_{3}{ }^{-}$ & $\mathbf{C O}_{3}{ }^{2-}$ & $\mathrm{Cl}^{-}$ & $\mathbf{M g}^{2+}$ & $\mathbf{N a}^{+}$ & $\mathbf{K}^{+}$ \\
\hline 6490 & 101 & 3 & 3330 & 53.7 & 9300 & 200 \\
\hline
\end{tabular}

\subsection{Experimental Unit}

A set of experiment unit was designed and assembled as shown in Figure 2, including experiment box, the interference circuit, and the test circuit. The experiment box was made by polypropylene (PP), and the dimensions were $20 \mathrm{~cm} \times 10 \mathrm{~cm} \times 8 \mathrm{~cm}$, entirely filled with soil sample. The working electrode (WE) was an X80 coupon. The counter electrode (CE) was a sheet of red copper with dimensions of $10 \mathrm{~cm} \times 8 \mathrm{~cm} \times 0.1 \mathrm{~cm}$, which fit in the box. The reference electrode (RE) was saturated calomel electrode (SCE, $+0.2415 \mathrm{~V} / \mathrm{SHE}$ at $25^{\circ} \mathrm{C}$ ). In the following sections of the article, electrochemical potentials were all expressed with respect to SCE. All the electrodes were immerged in the soil, together with a thermometer $1 \mathrm{~cm}$ away from $W E$.

In the interference circuit, WE and CE were connected with a customized electric power source, which could provide constant high DC voltage. A shunt resistor of $10 \Omega$ was in series with the power source, and a data logger was installed to monitoring the voltage across the shunt resistor. In the test circuit, WE, CE, and RE were connected by the Reference 3000 electrochemical workstation as a standard three-electrode cell. The soil spread resistance of the coupon was measured before and after interference.

All the tests were carried out at a temperature of $25 \pm 2{ }^{\circ} \mathrm{C}$ and a moisture of $30 \pm 2 \%$.

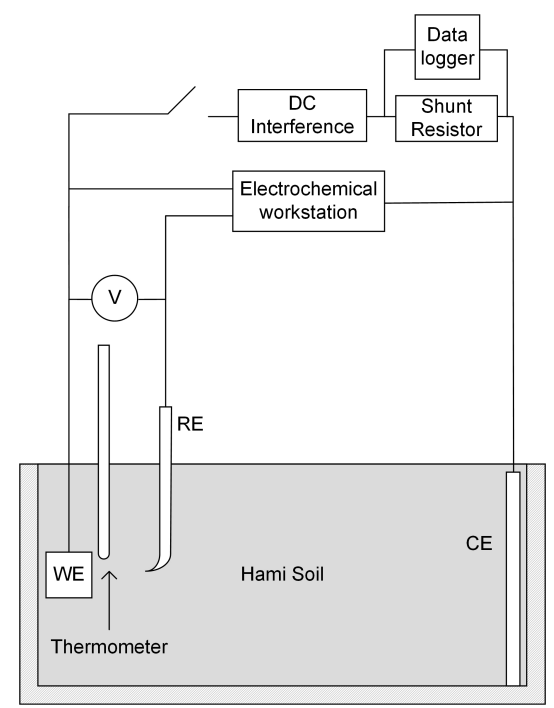

Figure 2. Schematic of the high voltage direct current (HVDC) interference and test system. 


\subsection{Techniques}

\subsubsection{Direct Current (DC) Interference Parameters Test}

Based on the interference parameters acquired from actual field, the interference potentials of 50, 100, 200, and $300 \mathrm{~V}$ were used to simulate HVDC interference. To simulate the real interference measured in the field test [15], the traditional galvanostatic polarization method was not used. For each experiment, the interference potential was controlled to be constant by the power source, and the data logger was used to constantly record the voltage drop of the shunt resistor at the frequency of $1 \mathrm{~Hz}$. The current density was then calculated as the voltage divided by the shunt resistance and the working area.

During the interference, the measured potential between WE and RE contained a large proportion of IR drop. Thus, in order to obtain the polarized potential of the coupon steel, current interruption method [16-18] was employed to eliminate the IR drop and obtain the real polarization potential $E_{\mathrm{p}}$ in our experiment.

\subsubsection{Local Soil Properties Test}

When the current flowing from soil to the coupon or from the coupon to surrounding soil, IR drop was produced between WE and RE in potential measurement $[19,20]$. The majority of the IR drop took place in the vicinity of the metal-to-soil interface. Thus, the concentration of the current flux lines shows a geometrical spread effect. Nielsen [21-25] proposed the conception of soil spread resistance $\left(R_{\mathrm{S}}\right)$, which could reflect the properties of the local soil around the coupon's surface. In this experiment, $R_{\mathrm{S}}$ was measured and calculated by applying an Alternative Current (AC) signal in the test cell by the workstation, as shown in the following equation:

$$
R_{\mathrm{s}}=\frac{U_{\mathrm{AC}}}{j_{\mathrm{AC}}}
$$

where $U_{\mathrm{AC}}$ and $j_{\mathrm{AC}}$ represent the $\mathrm{AC}$ voltage and the $\mathrm{AC}$ density.

During the interference, soil temperature was monitored by the thermometer $1 \mathrm{~cm}$ away from the coupon. After each interference, soil samples were taken out at the distance of $0.5,1,5,10$, and $20 \mathrm{~cm}$ away from the coupon. The water content was then measured by drying and weighing.

\subsubsection{Product Characterization}

After the interference of different voltages for $1 \mathrm{~h}$, and the interference of $300 \mathrm{~V}$ for different time, the corrosion products were characterized via Raman spectroscopy. The spectrometer was a LabRAM HR Evolution (HORIBA Ltd, Kyoto, Japan), with a $532 \mathrm{~nm}$ wavelength of an $\mathrm{Ar}^{+}$laser. The power was less than $1 \mathrm{~mW}$ in order to prevent transformation of the products.

\subsubsection{Corrosion Rate}

According to the ISO 8407: 2009 standard [26], the rust was eliminated by successive cleanings in inhibited hydrochloric acid aqueous solution $(500 \mathrm{~mL}$ de-ionized water $+500 \mathrm{~mL}$ concentrated hydrochloric acid $+5 \mathrm{~g}$ hexamethylenetetramine). The coupons were washed with acetone and de-ionized water and dried by air blast. The weight loss was measured and the corrosion rate $V$ was calculated by following equation:

$$
V=\frac{W_{\mathrm{b}}-W_{\mathrm{a}}-\Delta W_{0}}{t \rho A}
$$

where $W_{\mathrm{b}}$ and $W_{\mathrm{a}}$ are the coupon's weight before HVDC interference and after rust elimination, $\Delta W_{0}$ is the weight loss of blank sample during the rust elimination, $t$ is interference time, $\rho$ is the density of X80 steel. 


\section{Results}

\subsection{Interference Parameters}

The DC density was logged with time under 50-300 V HVDC interference, as shown in Figure 3a. The curves were similar to the measured ones in the field test, indicating the validity of simulation [15]. It could be seen that the current density experienced changes in three stages at different interference voltages. The DC densities all reached a peak just after the application of DC interference voltages and declined after a period of time. Taking the curve of $300 \mathrm{~V}$ as an example, the change in DC density with time could be divided into three stages, as shown in Figure 3b:

Stage 1: The fast increasing stage. The DC density climbed to a peak sharply in $3 \mathrm{~s}$ after the application of interference and the peak value was $315 \mathrm{~A} \cdot \mathrm{m}^{-2}$.

Stage 2: The fast decreasing stage. When the DC density reached a peak value, it began to decrease rapidly in $20 \mathrm{~s}$.

Stage 3: The stabilization stage. The DC density remained stable until the end of the interference. The curve decreased very slightly with little random fluctuation. The steady value of DC density was as low as $11 \mathrm{~A} \cdot \mathrm{m}^{-2}$, which was $1 / 29$ of the peak value. However, the duration was much longer that those in the above two stages.
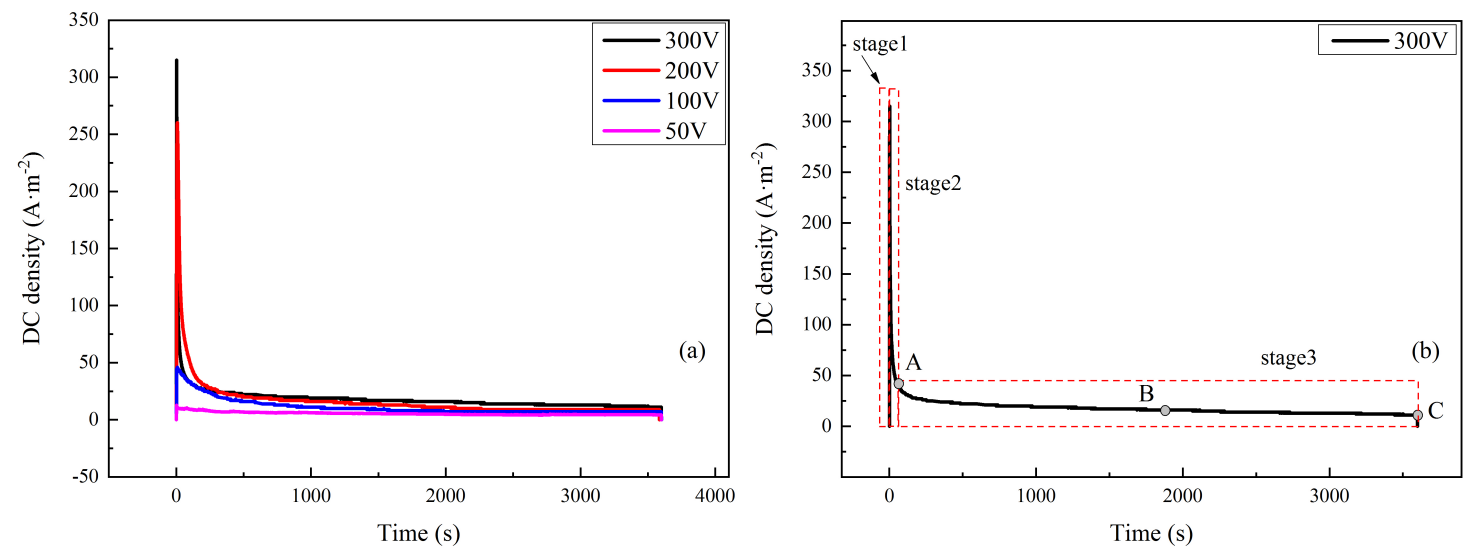

Figure 3. DC density-time transient of X80 coupons under 50-300 V (a) and 300 V DC voltages with three stages $(\mathbf{b})$.

Since the three stages of HVDC interference have seldom been reported, all experiments were repeated many times. This phenomenon appeared every time, and typical results are given here. To study the corrosion process, the corrosion products at different times along the DC density curve were tested. The times were shown by Points A, B, and C in Figure 3b, which represent times of 24, 1900 , and 3600 s respectively.

The peak values of Stage 2 and the steady values of Stage 3 are shown in Table 3. Both the peak value and the steady value increased with the interference voltage. The peak values of Stage 2 and the steady values of Stage 3 showed similar tendencies with interference voltage. As shown in Table 3, both values had a positive correlation with the interference voltage. When the interference voltage was $50 \mathrm{~V}$, the peak value and the steady value were the smallest, which were 12.8 and $4.4 \mathrm{~A} \cdot \mathrm{m}^{-2}$, respectively. When the interference voltage was $300 \mathrm{~V}$, the peak value was $315 \mathrm{~A} \cdot \mathrm{m}^{-2}$ and the steady DC density was $11 \mathrm{~A} \cdot \mathrm{m}^{-2}$.

The polarized potential $E_{\mathrm{p}}$, which was measured by the current interruption method, was also summarized in Table 3. $E_{\mathrm{p}}$ was closely related to the DC density just before the interruption. The higher the DC density, the more positive the $E_{\mathrm{p}}$. All the $E_{\mathrm{p}}$ values were far less than the interference voltages. The greatest value was measured after the peak of the DC density under $300 \mathrm{~V}$ interference, which was $1.052 \mathrm{~V}$. The significant difference between $E_{\mathrm{p}}$ and the interference voltage was attributed to the IR drop. 
Table 3. DC density values and corresponding $E_{\mathrm{p}}$.

\begin{tabular}{ccccc}
\hline $\begin{array}{c}\text { Interference } \\
\text { Voltage }\left(\mathbf{V}_{\mathbf{S C E}}\right)\end{array}$ & $\begin{array}{c}\text { Peak Value of } \mathbf{D C} \\
\text { Density }\left(\mathbf{A} \cdot \mathbf{m}^{-2}\right)\end{array}$ & $\begin{array}{c}E_{\mathbf{p}} \text { after the Peak } \\
\left(\mathbf{V}_{\mathbf{S C E}}\right)\end{array}$ & $\begin{array}{c}\text { Steady Value of } \\
\mathbf{D C} \text { Density } \\
\left(\mathbf{A} \cdot \mathbf{m}^{-2}\right)\end{array}$ & $\begin{array}{c}E_{\mathbf{p}} \text { at the End } \\
\left(\mathbf{V}_{\mathbf{S C E}}\right)\end{array}$ \\
\hline 50 & 12.8 & -0.335 & 4.4 & -0.603 \\
100 & 45 & -0.073 & 7 & -0.523 \\
200 & 260 & 0.992 & 9.5 & -0.429 \\
300 & 315 & 1.052 & 11 & -0.381 \\
\hline
\end{tabular}

\subsection{Corrosion Rate}

The weight loss was measured after rust elimination and the corrosion rate was calculated as shown in Table 4. It can be seen that the corrosion rate increased with the interference voltage. When the interference voltage was $300 \mathrm{~V}$, the corrosion rate was the highest, which was $2.055 \mu \mathrm{m} \cdot \mathrm{h}^{-1}$, or $16.56 \mathrm{~mm} \cdot$ year $^{-1}$. The corrosion rates were in the same order of the results in the literature [15]. Without the interference, the corrosion rate of the steel was $0.2 \mathrm{~mm} \cdot \mathrm{year}^{-1}$. It was quite low because of the dry environment.

Table 4. Weight loss and corrosion rates of X80 steel under 50-300 V HVDC interference.

\begin{tabular}{|c|c|c|c|}
\hline $\begin{array}{c}\text { Interference } \\
\left.\text { Voltage (V } \text { VCE }_{\text {SC }}\right)\end{array}$ & $\begin{array}{l}\text { Weight Loss } \\
\left(\mathrm{mg} \cdot \mathrm{cm}^{-2}\right)\end{array}$ & $\begin{array}{c}\text { Corrosion Rate } \\
\left(\mu \mathrm{m} \cdot \mathrm{h}^{-1}\right)\end{array}$ & $\begin{array}{c}\text { Corrosion Rate } \\
\left(\mathrm{mm} \cdot \text { year }^{-1}\right)\end{array}$ \\
\hline 50 & 0.504 & 0.638 & 5.589 \\
\hline 100 & 1.073 & 1.358 & 11.90 \\
\hline 200 & 1.493 & 1.890 & 16.56 \\
\hline 300 & 1.623 & 2.055 & 18.00 \\
\hline
\end{tabular}

\subsection{Local Soil Properties}

During the interference, the temperature of the local soil was measured. As shown in Figure 4, the temperature increased slightly at the interference voltage of 50 and $100 \mathrm{~V}$. However, at 200 and $300 \mathrm{~V}$, the temperature went up by more than $5^{\circ} \mathrm{C}$. This indicates that the higher the interference voltage is, the higher the heat generation from the corrosion reaction is. After a period of time, the soil temperature showed a slight downward trend, which may be related to the decline of the current density in Stage 3, compared with Stage 2. The temperature rise was due to the electrochemical reactions on the sample surface. It should be noted that the sample was only a point heat source compared with the geometry of the soil environment. The thermometer was placed $1 \mathrm{~cm}$ away from the coupon in order to minimize the impact on the current distribution. Thus, the measured temperature should lag behind the surface of the coupon metal and might be lower than the sample surface.

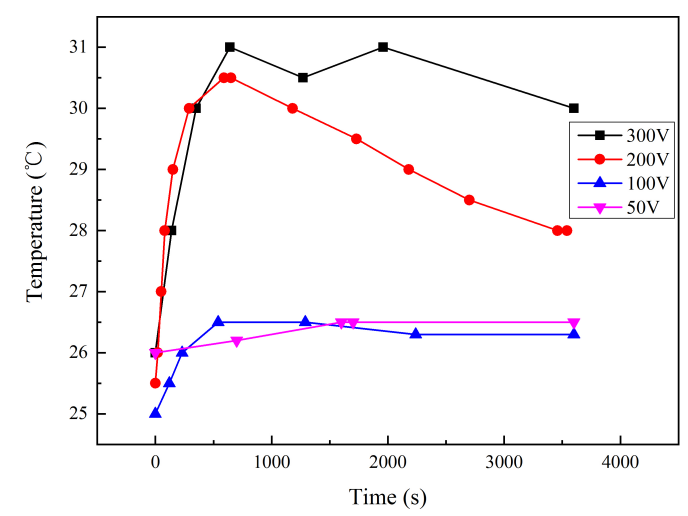

Figure 4. Local soil temperature-time transient $1 \mathrm{~cm}$ away from the coupon under HVDC interference. 
After the interference, the soil located $0.5,1,5,10$, and $20 \mathrm{~cm}$ away from the coupon was taken out. The soil water content was then measured, as shown in Figure 5. The dashed line represents the original water content, and the other point lines represent the water content after different HVDC interference. For each interference voltage, the soil water content $0.5 \mathrm{~cm}$ away from the coupon was the lowest. The water content increased gradually with the distance away from the coupon. However, the growth rate slowed. For each soil sample location, the higher the interference voltage was, the lower the water content was. The lowest water content was near the surface of the coupon after $300 \mathrm{~V}$ interference, which was just 5.54\%. In addition, all the water content at a distance of more than $10 \mathrm{~cm}$ from the coupons was very close to the original value. This indicated that the influence range of the corrosion process was less than $10 \mathrm{~cm}$.

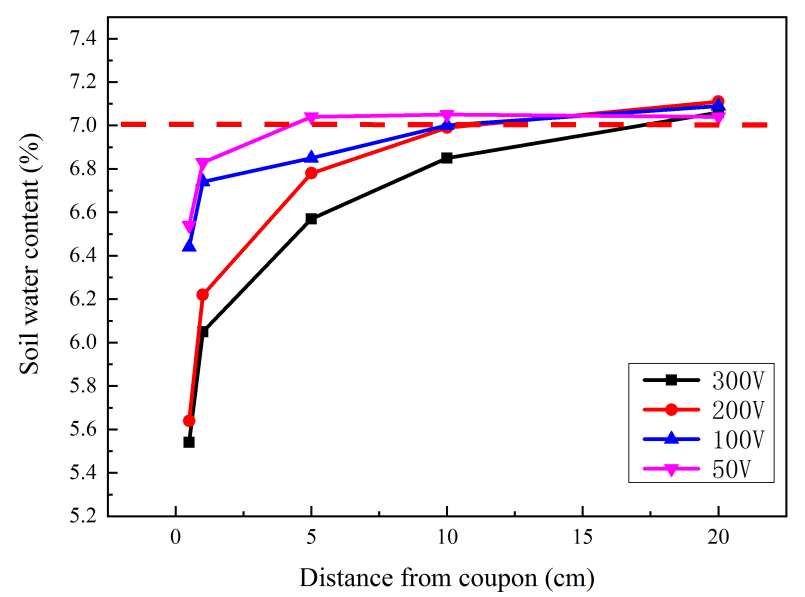

Figure 5. Soil water contents at different distances from coupon surface after different HVDC interferences.

The soil spread resistance $R_{\mathrm{S}}$ during the interference of $50-300 \mathrm{~V}$ is shown in Figure $6 . R_{\mathrm{S}}$ showed a great increase after interference was applied. For most of the time, the more interference voltage there was, the larger the $R_{\mathrm{S}}$ was. Before the application of interference, $R_{\mathrm{S}}$ was around $0.8 \Omega \cdot \mathrm{m}^{2}$. After the interference, $R_{\mathrm{S}}$ was $10.4,13.3,21.7$, and $26.3 \Omega \cdot \mathrm{m}^{2}$, respectively, corresponding to an interference voltage of 50, 100, 200, and $300 \mathrm{~V}$.

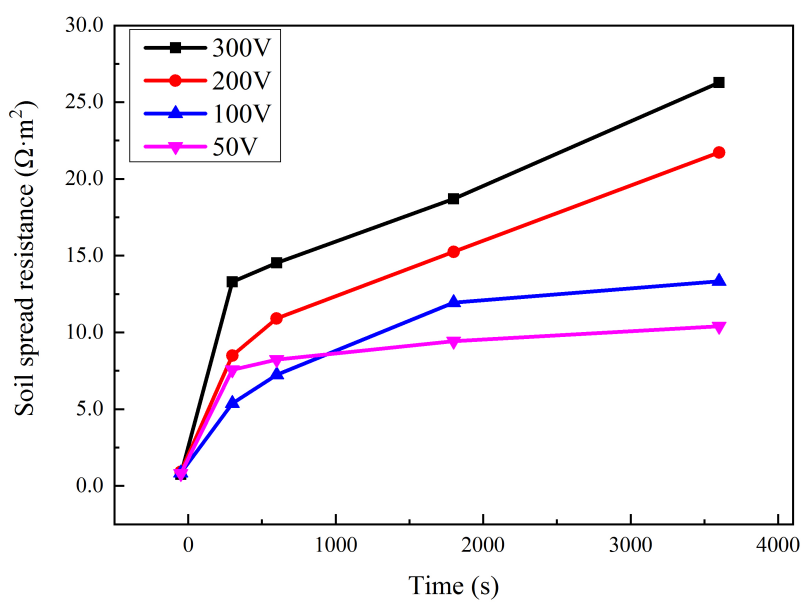

Figure 6. Variation of $R_{\mathrm{S}}$ during HVDC interference.

\subsection{Surface Characterization}

The macro morphologies of the coupon surface under different interference voltage and time are exhibited in Figure 7. Figure 7a-d shows the coupons after the $1 \mathrm{~h}$ interference of 50, 100, 200, and $300 \mathrm{~V}$. The corrosion products were mainly reddish brown. Figure 7e,f shows the coupons under $300 \mathrm{~V}$ 
interference for 24 and $1900 \mathrm{~s}$. The colors of the rust were black and dark brown, respectively. All the rust was loose in texture. It did not contact with the basic metal tightly and could be washed with water easily. Therefore, some of the corrosion products fell off when taking out the coupons from soil.

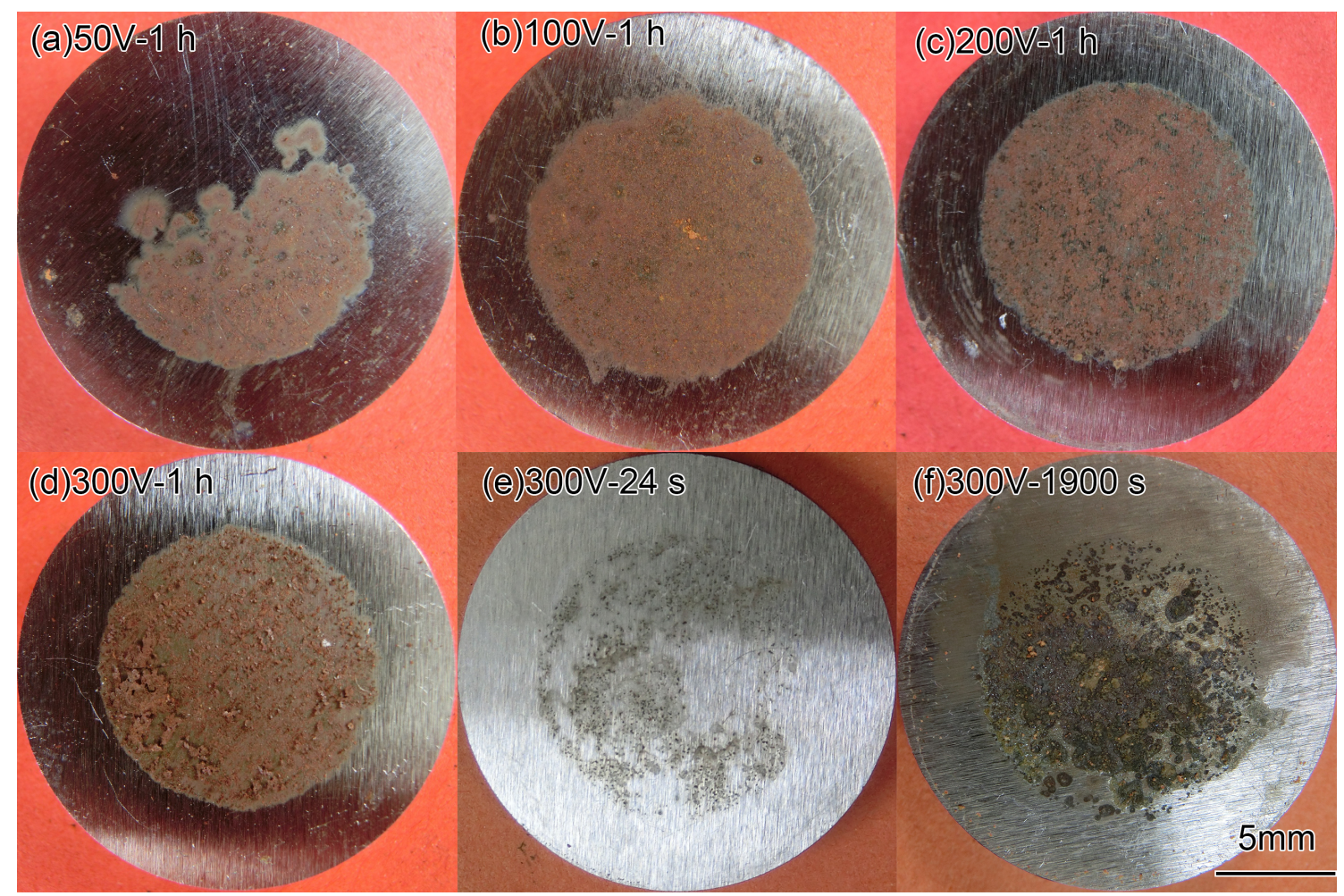

Figure 7. Macro morphologies of X80 steel coupons after HVDC interference.

It could be seen that, at $24 \mathrm{~s}$ of the interference (the end of Stage 2), the corrosion products were scattered at the surface. At $1900 \mathrm{~s}$ (the middle of Stage 3), the corroded area accreted and the corrosion products increased. After the interference of $1 \mathrm{~h}$, the products were well-distributed. It can be inferred that the corrosion process was a gradual development. The non-uniform corrosion growth at the initial stage was due to the uneven contact between the coupon metal and the sandy soil, which had high porosity and low water content. It is obvious that the current density of the contact part should be higher than the average one. With the prolongation of the interference time, the corrosion position was gradually connected and the corrosion products increased.

The corrosion products were characterized via Raman spectra. Figure 8 shows the spectra results of rust after the interference of 50,100, 200, and $300 \mathrm{~V}$. The curves were of a similar shape, which indicates that the products were quite similar. The main peaks were located at 215, 285, 390, 605, and $1300 \mathrm{~cm}^{-1}$, and the strongest peak appeared at 215 and $285 \mathrm{~cm}^{-1}$. Based on other Raman spectra analysis of rust and iron oxide compound [27-30], the corrosion products of HVDC interference in this experiment were characterized to be hematite $\left(\alpha-\mathrm{Fe}_{2} \mathrm{O}_{3}\right)$. Other metal oxides were not detected because of the low concentration of alloying elements. In addition, no chloride or sulfate products were characterized, indicating that the anions did not play a prominent role in HVDC interference. 


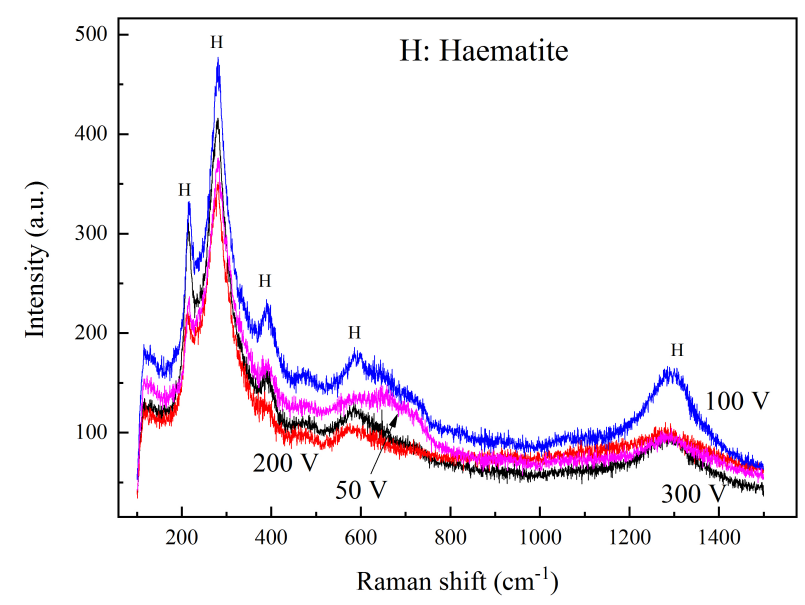

Figure 8. Raman spectra of corrosion products after 50 300 V HVDC interference of $1 \mathrm{~h}$.

The Raman spectra of the coupons under 300 V HVDC interference for different times are shown in Figure 9. At $24 \mathrm{~s}$, the corrosion products were hematite and lepidocrocite $(\gamma-\mathrm{FeOOH})$. The lepidocrocite had strong peaks at 250,650, and $1055 \mathrm{~cm}^{-1}[27,28]$, which could be distinguished clearly from the hematite. At $1900 \mathrm{~s}$, the corrosion products still consisted of hematite and lepidocrocite. However, the intensity of the lepidocrocite's peaks reduced. The peaks at 250 and $1055 \mathrm{~cm}^{-1}$ were not easy to recognize from the background noise. After the interference of $1 \mathrm{~h}$, the corrosion products were all hematite, which was mentioned above. The results of Raman spectra indicate that the corrosion mechanism was not the same at different stages of DC density. The lepidocrocite was generated with a large DC density in Stage 2, but it transformed into hematite with a small DC density in Stage 3.

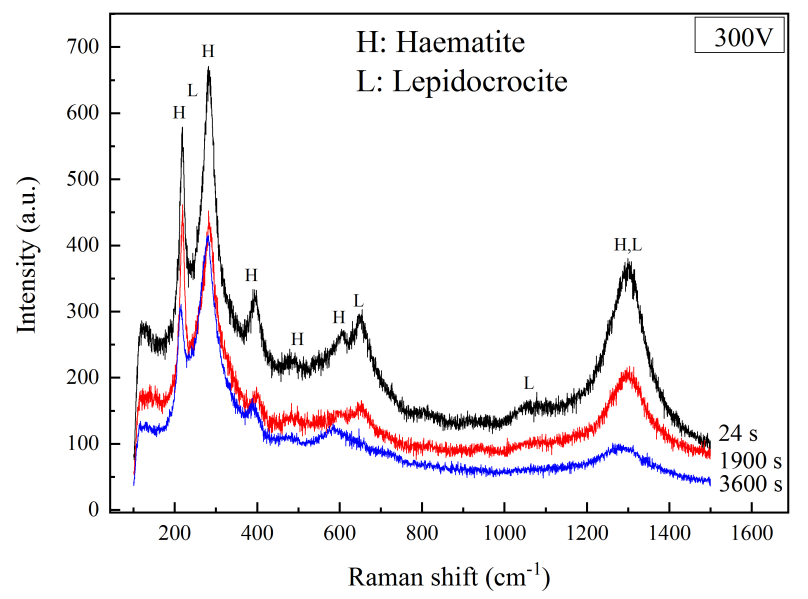

Figure 9. Raman spectra of corrosion products after $300 \mathrm{~V}$ HVDC interference at different times.

\section{Discussion}

\subsection{Reasons for DC Density Changes under HVDC Interference}

During HVDC interference, the DC density had a rapid decline in Stage 2, as mentioned above. This rapid decline process was closely related to the change in soil properties near the surface of the coupons during HVDC interference.

In the potential test, when the external current flowed through the coupon, the measured potential included the IR drop of electrolyte, as shown in Equation (3) [25,31]:

$$
E_{\mathrm{on}}=E_{\mathrm{p}}+j_{\mathrm{DC}} R_{\mathrm{s}}
$$

where $E_{\mathrm{on}}$ and $j_{\mathrm{DC}}$ represent the on-potential, and the DC density, $j_{\mathrm{DC}} R_{\mathrm{S}}$ was the IR drop of electrolyte. 
In this work, the measured on-potential remained almost unchanged during the interference. In addition, the $E_{\mathrm{p}}$ was far less than the on-potential, which is shown in Table 3. Therefore, Equation (3) can be modified into Equation (4):

$$
j_{\mathrm{DC}}=\frac{E_{\mathrm{on}}-E_{\mathrm{p}}}{R_{\mathrm{os}}} \approx \frac{E_{\mathrm{on}}}{R_{\mathrm{s}}}
$$

Equation (4) indicates that, during the HVDC interference, $j_{\mathrm{DC}}$ was inversely proportional to $R_{\mathrm{S}}$. As shown in Figure $7, R_{\mathrm{S}}$ increased dozens of times, which corresponded to the sharp decrease in the DC density. On the other hand, in HVDC interference, the magnitude of the IR drop was so great that it was the predominant part of the $E_{\text {on }}$. Thus, the sharp decrease in DC density in the HVDC interference process was caused by the large increase in $R_{\mathrm{S}}$.

As for the characteristics of $R_{\mathrm{S}}$, it had a linear relationship with the soil resistivity [22,25]. Hence, soil with different water content was prepared by drying and adding deionized water. Soil resistivity was then measured using the soil box, and the result is shown in Figure 10. In this figure, soil resistivity had exponential increase with the linear decrease in water content. This indicates that a small decrease in water content could cause a significant increase in $R_{\mathrm{s}}$. This coincided with the results shown in Figures 5 and 6. In addition, due to the concentration of the external current near the coupon surface, $R_{\mathrm{S}}$ mainly reflected the properties of the soil very close to the coupon, especially the soil temperature and the ion properties. Some authors $[32,33]$ believe that the external DC density will affect the ion concentration and ion transference number and thus affect the soil resistivity. Some researchers [34,35] pointed out that high DC density will induce heat and water evaporation in soil, resulting in significant increase in soil resistivity.

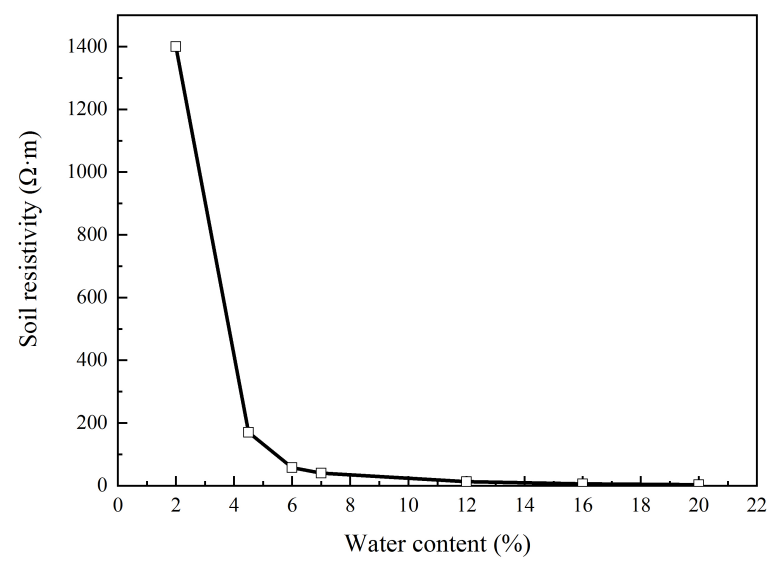

Figure 10. Soil resistivity with water content.

The result indicates that the change in DC density was due to the characteristics of nearby soil, instead of the corrosion products. This has seldom been reported. On the basis of the above analyses, the reasons for the change in DC density could be explained as follows:

Stage 1: At the start of the interference, the electrochemical reaction occurring on the surface of the coupon was forced by the high DC voltage. Therefore, the DC density climbed to peak value sharply.

Stage 2: The high current density caused a strong reaction, which released a great deal of heat on the metal surface. The heat was then conducted to the soil, accelerating the water evaporation. In the soil near the coupon, a tiny decrease in water content could lead to huge growth in soil resistivity and soil spread resistance. In this way, the DC density had a sharp decline.

Stage 3: When the DC density decreased to a certain value (the steady value), the generated heat was reduced, reaching heat conduction equilibrium with the surrounding soil. Meanwhile, the water evaporation and permeation reached equilibrium. In this way, the spread resistance was almost unchanged and the DC density remained steady. 


\subsection{Corrosion Behavior of X80 Steel under HVDC Interference in Sandy Soil}

The Raman spectra of the rusts showed a generation and transformation process of lepidocrocite. Lepidocrocite could not be produced from iron directly in one step, and it should have some intermediate products, which had been studied substantially [36-39].

Classically, the first step of iron corrosion was described as the oxidization to dissolve ferrous ions:

$$
\mathrm{Fe}=\mathrm{Fe}^{2+}+2 \mathrm{e}
$$

At Stages 1 and 2, since the external DC density was high, the polarized potential $E_{\mathrm{p}}$ grew positively, and the ferrous ions could be oxidized further on the metal surface by DC density [40,41]. This was clearly described by the E-pH relationship in the literature [42]. The reaction would take place when $E_{\mathrm{p}}$ was positive than $1.0115 \mathrm{~V}$ :

$$
\mathrm{Fe}^{3+}=\mathrm{Fe}^{2+}+\mathrm{e}
$$

The redox potential E of Equation (6) was described as [19]

$$
E=E_{0}+\frac{R T}{2 F} \ln \frac{a_{\mathrm{Fe}^{3+}}}{a_{\mathrm{Fe}^{2+}}}
$$

where the $E_{0}$ represents the standard redox potential of Equation (6), which is $1.0115 \mathrm{~V}_{\mathrm{SCE}} . R, T$, and $F$ represent the gas constant, temperature, and Faraday constant, respectively.

To be specific, the $E_{\mathrm{p}}$ was $1.052 \mathrm{~V}_{\mathrm{SCE}}$ after the peak of DC density in $300 \mathrm{~V}$ interference, shown in Table 3. Thus, $\mathrm{a}_{\mathrm{Fe}^{3+}} / \mathrm{a}_{\mathrm{Fe}^{2+}}$ was calculated to be 23.8 according to Equation (7). This indicates that the ferric ions were the dominant species at the initial stage of HVDC interference, which was characterized as a high DC density.

The ferric ions then combined with the hydroxyl ions in water and precipitated:

$$
\mathrm{Fe}^{3+}+3 \mathrm{OH}^{-}=\mathrm{Fe}(\mathrm{OH})_{3}
$$

With the evaporation of the water in the soil discussed above, the ferric hydroxide was unstable in this dry environment. The dehydration reaction would take place:

$$
\mathrm{Fe}(\mathrm{OH})_{3}=\gamma-\mathrm{FeOOH}(\text { lepidocrocite })+\mathrm{H}_{2} \mathrm{O}
$$

With the temperature rise and the soil water content drop in Stage 2 of the DC density, lepidocrocite was further dehydrated to hematite, which is shown in Equation (10) [39]. In this way, lepidocrocite and hematite was all characterized at $24 \mathrm{~s}$ of the interference.

$$
\gamma-\mathrm{FeOOH}=\alpha-\mathrm{Fe}_{2} \mathrm{O}_{3}(\text { hematite })+\mathrm{H}_{2} \mathrm{O}
$$

At Stage 3, the DC density was relatively low, and the $E_{\mathrm{p}}$ was lower than $E_{0}$. Thus, Equation (6) was impossible thermodynamically. The valence rise of ferrous ions was due to the oxidization of oxygen, which was sufficient because of the high porosity of the sandy soil. The reactions could be deduced as follows:

$$
\begin{gathered}
\mathrm{Fe}^{2+}+2 \mathrm{OH}^{-}=\mathrm{Fe}(\mathrm{OH})_{2} \\
2 \mathrm{Fe}(\mathrm{OH})_{2}+\frac{1}{2} \mathrm{O}_{2}=\alpha-\mathrm{Fe}_{2} \mathrm{O}_{3}+2 \mathrm{H}_{2} \mathrm{O}
\end{gathered}
$$

Based on the analysis above, the corrosion behavior of X80 steel under HVDC interference in sandy soil was proposed and modeled as shown in Figure 11. At Stage 1, the DC density was high, generating great heat. The soil temperature and $R_{\mathrm{s}}$ rose rapidly, which led to the decline of DC density in Stage 2. When the DC density was relatively high, the ferrous ions were oxidized to ferric ions by 
the external DC density directly, and lepidocrocite was produced. At Stage 3, the DC density was low, which was due to the equilibrium of heat generation and conduction, as well as the equilibrium of water evaporation and penetration. The ferrous ions were oxidized by oxygen and the final products were hematite.
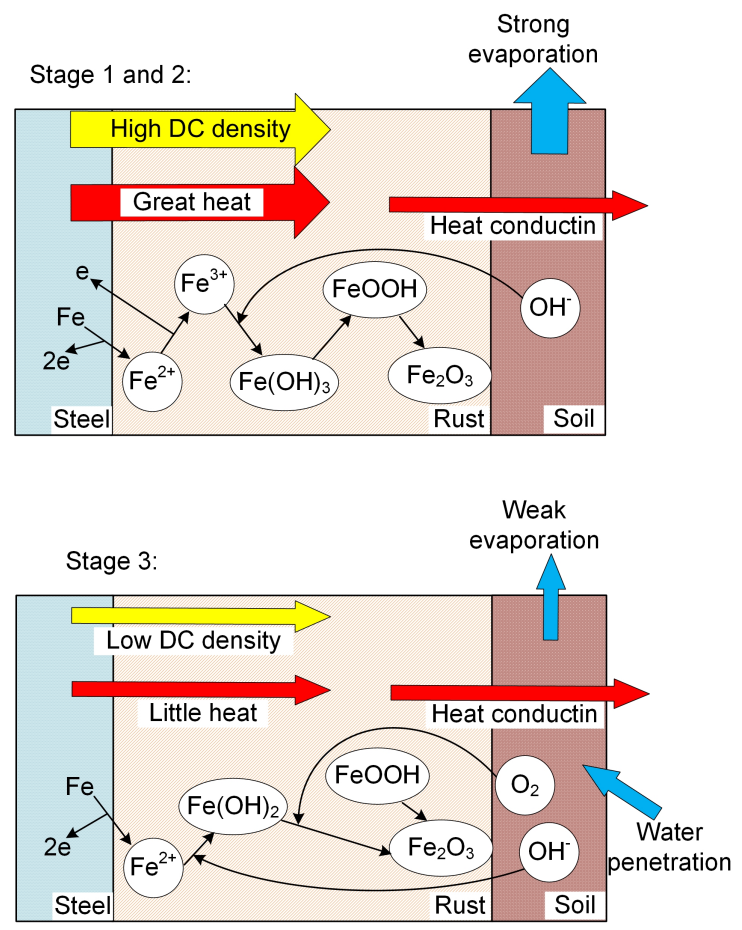

Figure 11. Simplified schematic of corrosion behavior of $X 80$ steel under HVDC interference in sandy soil.

\subsection{Correlation between Corrosion Rate and DC Density}

In some DC interference cases of the metro system, the DC density fluctuated, and the corrosion rates could not be deduced from the DC density. However, in the HVDC interference, though the DC density had great changes, the corrosion rate was directly related to the DC density.

To testify, the corrosion rate was calculated. The Faraday's law describes the relation of the reaction rate and the external DC density. According to Faraday's law, the instant reaction rate $R_{\text {ins }}$ is

$$
R_{\mathrm{ins}}=\frac{j_{\mathrm{DC}}}{n F}
$$

where $j_{\mathrm{DC}}$ is the DC density, $n$ is the stoichiometric number of electrons consumed in the electrode reaction.

Take Equations (5) and (6) into consideration, the corrosion rate $R_{\text {cor }}$ of X80 steel under HVDC interference was calculated by integrating the DC density curves:

$$
R_{\mathrm{cor}}=\frac{\int R_{\mathrm{ins}} \mathrm{M} \cdot d t}{t \rho}
$$

where $M$ is the mole mass of the reactants, which is 56 in this case, and $t$ is the reaction time.

The measured and calculated corrosion rates under 50,100, 200, and $300 \mathrm{~V}$ interference are shown in Figure 12. The calculated values fit well, which meant good coherence between the corrosion rates and DC density. 


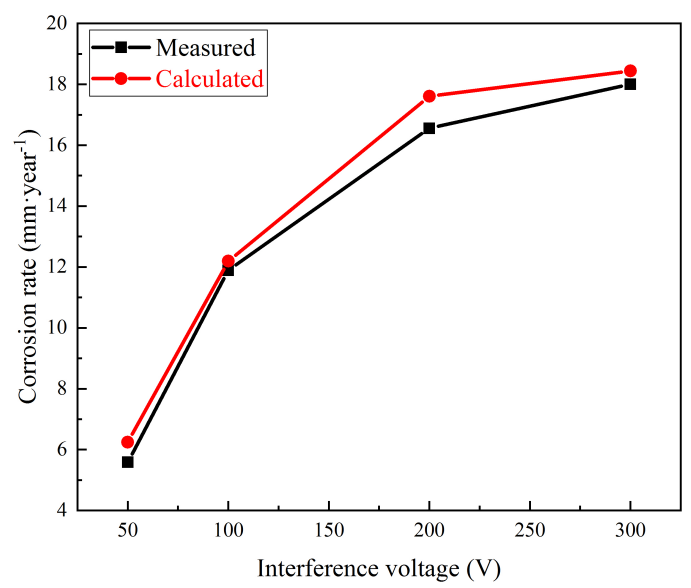

Figure 12. Measured and calculated corrosion rates under HVDC interference.

\section{Conclusions}

When the X80 coupons were under 50,100, 200, and $300 \mathrm{~V}$ of HVDC interference in the sandy soil, the corrosion rates were $5.59,11.90,16.56$, and $18.00 \mathrm{~mm} \cdot$ year $^{-1}$, respectively. The corrosion rates were directly related to the DC density.

During the interference, the DC density typically underwent three stages: first, it sharply increased to peak value in a few seconds, it decreased rapidly to a steady value over dozens of seconds, and it finally remained steady for the remaining time. The DC density affected, and was affected by, the local environment. The decline of the DC density in Stage 2 was mainly due to the soil temperature increment, the water content decrement, and the substantial growth in soil spread resistance. This was a special feature of the soil corrosion under HVDC interference.

At Stages 1 and 2, the DC density was relatively high. The steel could be oxidized to ferric ions directly by the DC density. The lepidocrocite was formed on the sample surface. It then dehydrated to hematite. At Stage 3, the DC density stayed lower. The ferric ions could not be produced directly. The ferrous ions were oxidized by oxygen. After the HVDC interference, the final product of X80 steel was hematite.

Author Contributions: Conceptualization, Y.D. and R.Q.; methodology, Y.D. and R.Q.; writing-original draft preparation, R.Q.; writing — review and editing, Z.J. and Y.L.; funding acquisition, X.W. and A.F.

Funding: This research was funded by National Key R\&D Program of China, grant number 2016YFC0802101.

Acknowledgments: The authors would like to acknowledge the National Key R\&D Program of China (grant number 2016YFC0802101).

Conflicts of Interest: The authors declare no conflict of interest.

\section{References}

1. Zhang, C.; Chu, X.; Zhang, B.; Ma, L.; Li, X.; Wang, X.; Wang, L.; Wu, C. A coordinated DC power support strategy for multi-Infeed HVDC systems. Energies 2018, 11, 1637. [CrossRef]

2. Marzinotto, M.; Mazzanti, G.; Nervi, M. Ground/sea return with electrode systems for HVDC transmission. Int. J. Electr. Power Energy Syst. 2018, 100, 222-230. [CrossRef]

3. Bahrman, M.P.; Johnson, B.K. The ABCs of HVDC transmission technologies. IEEE Power Energy Mag. 2007, 5, 32-44. [CrossRef]

4. Shu, Y.; Liu, Z.; Gao, L.; Wang, S. A preliminary exploration for design of $\pm 800 \mathrm{kV}$ UHVDC project with transmission capacity of 6400 MW. Power Syst. Technol. 2006, 30, 1-8.

5. Hwang, S.; Lee, J.; Jang, G. HVDC-system-interaction assessment through line-flow change-distribution factor and transient-stability analysis at planning stage. Energies 2016, 9, 1068. [CrossRef] 
6. Van Eeckhout, B.; Van Hertem, D.; Reza, M.; Srivastava, K.; Belmans, R. Economic comparison of VSC HVDC and HVAC as transmission system for a $300 \mathrm{MW}$ offshore wind farm. Eur. Trans. Electr. Power 2010, 20, 661-671. [CrossRef]

7. Verhiel, A.L. The effects of high-voltage dc power transmission systems on buried metallic pipelines. IEEE Trans. Ind. Appl. 1971, 3, 403-415. [CrossRef]

8. Nicholson, E. High voltage direct current interference with underground/underwater pipelines. In Proceedings of the Corrosion Conference 2010, San Antonio, TX, USA, 14-18 March 2010. No. 10102.

9. Caroli, C.E.; Santos, N.; Kovarsky, D.; Pinto, L.J. ITAIPU HVDC ground electrodes: Interference considerations and potential curve measurements during Bipole II commissioning. IEEE Trans. Power Deliv. 1990, 5, 1583-1590. [CrossRef]

10. Offermann, P.F.; Schrem, F.W. The effect of HVDC ground current on oil field corrosion. IEEE Trans. Ind. Appl. 1968, 3, 260-266. [CrossRef]

11. Hopper, A.T.; Gideon, D.N.; Berry, W.E. Analysis of the Effects of High-Voltage Direct-Current Transmission Systems on Buried Pipelines; Technical Toolboxes: Houston, AK, USA, 1967.

12. Bi, W.; Chen, H.; Li, Z.; Jiang, Y.; Liu, L.; Hu, Y. HVDC interference to buried pipeline: Numerical modeling and continuous P/S potential monitoring. In Proceedings of the Corrosion Conference 2016, Vancouver, BC, Canada, 6-10 March 2016. No. 7714.

13. $\mathrm{Li}, \mathrm{Z}$. Field test and analysis of interference of high or ultra high voltage direct current transmission system to underground steel pipeline. Corros. Prot. 2017, 38, 142-150.

14. Gong, Y.; Xue, C.; Yuan, Z.; Li, Y.; Dawalibi, F.P. Advanced analysis of HVDC electrodes interference on neighboring pipelines. J. Power Energy Eng. 2015, 3, 332-341. [CrossRef]

15. Qin, R.Z.; Du, Y.X.; Peng, G.Z.; Lu, M.X.; Jiang, Z.T. High Voltage Direct Current interference on buried pipelines: Case study and mitigation design. In Proceedings of the Corrosion Conference 2017, New Orleans, LA, USA, 28-31 March 2017.

16. Elsener, B. Corrosion rate of steel in concrete-Measurements beyond the Tafel law. Corros. Sci. 2005, 47, 3019-3033. [CrossRef]

17. McIntyre, J.D.E.; Peck, W.F. An interrupter technique for measuring the uncompensated resistance of electrode reactions under potentiostatic control. J. Electrochem. Soc. 1970, 117, 747-751. [CrossRef]

18. Oelßner, W.; Berthold, F.; Guth, U. The iR drop-well-known but often underestimated in electrochemical polarization measurements and corrosion testing. Mater. Corros. 2006, 57, 455-466. [CrossRef]

19. Bard, A.J.; Faulkner, L.R. Electrochemical Methods: Fundamentals and Applications; Wiley: New York, NY, USA, 2001.

20. Marcus, P. Corrosion Mechanisms in Theory and Practice; Marcel Dekker: New York, NY, USA, 2002.

21. Nielsen, L.V.; Nielsen, K.V.; Baumgarten, B. AC induced corrosion in pipelines: Detection, characterization and mitigation. In Proceedings of the Corrosion Conference 2004, New Orleans, LA, USA, 28-31 March 2004. No.04211.

22. Nielsen, L.V.; Galsgaard, F. Sensor technology for on-line monitoring of AC induced corrosion along pipelines. In Proceedings of the Corrosion Conference 2005, Houston, AK, USA, 3-7 April 2005; No. 05375.

23. Nielsen, L.V.; Nielsen, K.V. Differential ER-technology for measuring degree of accumulated corrosion as well as instant corrosion rate. In Proceedings of the Corrosion Conference 2003, San Diego, CA, USA, 3-7 March 2003; No.03443.

24. Nielsen, L.V. Role of alkalization in AC induced corrosion of pipelines and consequences hereof in relation to CP requirements. In Proceedings of the Corrosion Conference 2005, Houston, AK, USA, 3-7 April 2005; No. 05188.

25. Nielsen, L.V.; Cohn, P. AC-corrosion and electrical equivalent diagrams. In Proceedings of the CEOCOR 2000, Brussels, Belgium, 9-12 May 2000.

26. ISO 8407:2009. Corrosion of Metals and Alloys-Removal of Corrosion Products from Corrosion Test Specimens; International Organization for Standardizatino: Geneva, Switzerland, 2009.

27. Froment, F.; Tournié, A.; Colomban, P. Raman identification of natural red to yellow pigments: Ochre and iron-containing ores. J. Raman Spectrosc. 2008, 39, 560-568. [CrossRef]

28. Dünnwald, J.; Otto, A. An investigation of phase transitions in rust layers using Raman spectroscopy. Corros. Sci. 1989, 29, 1167-1176. [CrossRef] 
29. Singh, D.D.N.; Yadav, S.; Saha, J.K. Role of climatic conditions on corrosion characteristics of structural steels. Corros. Sci. 2008, 50, 93-110. [CrossRef]

30. Chitra, P.; Rajaram, R.; Venkatesh, P. Raman identification of corrosion products on automotive galvanized steel sheets. J. Raman Spectrosc. 2010, 39, 881-886.

31. Nielsen, L.V.; Baumgarten, B.; Cohn, P. Investigating AC and DC stray current corrosion. In Proceedings of the CeoCor 2005, Malmoe, Sweden, 31 May-5 June 2005.

32. Cao, X.; Wu, G.; Fu, L.; Jiang, W.; Zhang, X. The impact of dc current density on soil resistivity. Proc. Chin. Soc. Electr. Eng. 2008, 28, 37-42.

33. Huang, Z.; Wu, G.; Jiang, W.; Xiao, H.; Guan, L. Study of the influences on soil resistivity caused by HVDC mono-polar operation. In Proceedings of the International Conference on High Voltage Engineering and Application, Chongqing, China, 9-13 November 2009; pp. 232-236.

34. Sima, W.; Luo, L.; Yuan, T.; Yang, Q.; Tang, Y.; Zhou, Y. Experimental analysis on the change regulation of the soil resistivity considering the thermal effect around the grounding electrode. In Proceedings of the Asia-Pacific International Conference on Lightning, Chengdu, China, 2-4 November 2011; pp. 673-676.

35. Sima, W.; Luo, L.; Yuan, T.; Yang, Q.; Lei, C.; Jiang, C. Temperature characteristic of soil resistivity and its effect on the DC grounding electrode heating. High Volt. Eng. 2012, 38, 1192-1198.

36. Yan, M.; Sun, C.; Xu, J.; Dong, J.; Ke, W. Role of Fe oxides in corrosion of pipeline steel in a red clay soil. Corros. Sci. 2014, 80, 309-317. [CrossRef]

37. Daub, K.; Zhang, X.; Wang, L.; Qin, Z.; Noel, J.J.; Wren, J.C. Oxide growth and conversion on carbon steel as a function of temperature over 25 and $80^{\circ} \mathrm{C}$ under ambient pressure. Electrochim. Acta 2011, 56, 6661-6672. [CrossRef]

38. Xu, W.; Daub, K.; Zhang, X.; Noel, J.J.; Shoesmith, D.W.; Wren, J.C. Oxide formation and conversion on carbon steel in mildly basic solutions. Electrochim. Acta 2009, 54, 5727-5738. [CrossRef]

39. Cornell, R.M.; Schwertmann, U. The Iron Oxides: Structure, Properties, Reactions, Occurrences and Uses; Wiley: New York, NY, USA, 2003.

40. Datta, M. Anodic dissolution of metals at high rates. IBM J. Res. Dev. 1993, 37, 207-226. [CrossRef]

41. Baranwal, P.K.; Prasanna Venkatesh, R. Investigation of carbon steel anodic dissolution in ammonium chloride solutions using electrochemical impedance spectroscopy. J. Solid State Electrochem. 2017, 21, 1373-1384. [CrossRef]

42. Ruby, C.; Géhin, A.; Aissa, R.; Génin, J.M.R. Mass-balance and Eh-pH diagrams of Fe II-III green rust in aqueous sulphated solution. Corros. Sci. 2006, 48, 3824-3837. [CrossRef] 